\title{
Green synthesis of propylene oxide directly from propane
}

Pierre Kube, ${ }^{1}$ Jinhu Dong, ${ }^{1}$ Toyin Omojola, ${ }^{1}$ Nuria Sánchez Bastardo, ${ }^{2}$ Holger Ruland, ${ }^{2}$

Robert Schlögl, ${ }^{1,2}$ and Annette Trunschke ${ }^{1, *}$

${ }^{\text {I} F r i t z-H a b e r-I n s t i t u t ~ d e r ~ M a x-P l a n c k-G e s e l l s c h a f t, ~ D e p a r t m e n t ~ o f ~ I n o r g a n i c ~ C h e m i s t r y, ~ F a r a d a y w e g ~ 4-~}$ 6, 14195 Berlin (Germany).

${ }^{2}$ Max-Planck-Institut für Chemische Energiekonversion, Department of Heterogeneous Reactions, Stiftstrasse 34-36, 45470 Mülheim an der Ruhr.

kube@fhi-berlin.mpg.de

jhdong@fhi-berlin.mpg.de

omojola@fhi-berlin.mpg.de

nuria.sanchez-bastardo@cec.mpg.de

holger.ruland@cec.mpg.de

rs01@fhi-berlin.mpg.de

corresponding author: trunschke@fhi-berlin.mpg.de 
The chemical industry faces the challenge of bringing emissions of climate-damaging $\mathrm{CO}_{2}$ to zero. $^{1,2}$ However, the synthesis of important intermediates, such as olefins or epoxides, is still associated with the release of large amounts of greenhouse gases. This is due to both a high energy input for many process steps and insufficient selectivity of the underlying catalysed reactions. Surprisingly, we found that the oxidation of propane at elevated temperature over inert materials such as boron nitride and silicon dioxide leads to the formation of significant amounts of propylene oxide in a mixture with propylene, with unexpectedly small amounts of $\mathrm{CO}_{2}$ being formed. Fragile products are usually synthesised on highly specific surfaces, which is associated with strong interactions. We demonstrate that rapid reaction over unspecific interfaces entails important consequences for the synthesis of products prone to overoxidation. Process simulations reveal that the combined synthesis of these two important chemical building blocks is technologically feasible. Our discovery leads the ways towards an environmentally friendly production of propylene oxide and propylene in one step. A complex catalyst development is not necessary. 


\section{Main}

The discovery of new heterogeneous catalysts requires creative approaches in materials synthesis, ${ }^{3}$ but likewise the application of a broad parameter field in catalyst testing. ${ }^{4,5}$ The process conditions have a strong influence on the formation of the catalyst and on the structure of the reaction network. Depending on the reaction parameters, different active phases can be generated. At the same time, the interaction of the various surface centres with intermediates of gas phase reactions must be considered. These complex interrelations influence the entire reaction kinetics and can lead to different functional properties of one and the same catalyst precursor. Dynamic surface reconstructions and entangled reaction networks thus evoke an enormous complexity that must be taken into account in descriptor- and big-data-based searches for new functional materials. ${ }^{6,7}$ Herein we demonstrate how inert materials can be used as a process component for upgrading propane, which is abundant as a raw material but inert, directly into the valuable chemical intermediates propylene and propylene oxide (PO) by optimizing the process conditions rather than the sorption properties of the interface.

Propylene, as a key building block of the chemical industry, was produced globally at a scale of 130 million metric tonnes in 2019. ${ }^{8}$ Propylene oxide is a major intermediate in the chemical industry for producing a large variety of consumer products including polyether polyols that are used in the manufacture of polyurethanes, propylene glycols as raw materials for the production of unsaturated polyester resins applied in the textile and construction industries, and propylene glycol ethers utilized as solvents in paints, inks, coatings and many other related applications. ${ }^{9}$ Large-scale production of propylene oxide (globally approximately 10 million t/y in 2012) starts from propylene produced from crude oil fractions by steam cracking or fluid catalytic cracking (FCC). About $10 \%$ of all produced propylene is used for the manufacture of propylene oxide using three main production technologies including the chlorhydrine process, coproduct routes, and liquid-phase epoxidation of propylene with hydrogen peroxide in methanol as solvent at $30-80^{\circ} \mathrm{C}$ and $10-30$ bar over a titanium silicalite (TS-1) catalyst. ${ }^{9,10}$ The need of 
expensive auxiliary chemicals such as hydrogen peroxide, the complexity of the processes, and considerable environmental burdens due to waste formation imply economic drawbacks of the current multistep production technologies. Hence, direct synthesis of propylene oxide using molecular oxygen attracted great interest, ${ }^{11}$ and the challenging task initiated ground-breaking research. ${ }^{12,13}$ Supported Ag catalysts modified by promoters and $\mathrm{TiO}_{2}$-based systems exhibit good prospects in heterogeneous oxidation of propylene by $\mathrm{O}_{2}$. However, although the activity of the $\mathrm{TiO}_{2}$-based catalysts is higher compared to Ag systems, the selectivity to propylene oxide is too low for an industrial application in both cases. $^{11}$

\section{Selective oxidation of propane}

In our investigation of transition metal-free catalysts in direct oxidation of alkanes, hexagonal boron nitride was reconsidered that has been reported to show activity and high selectivity in the oxidative dehydrogenation of propane to propylene, ${ }^{14,15}$ and in oxidative dehydrogenation of other substrates. ${ }^{16-18} \mathrm{We}$ compared the performance of $h$-BN in propane oxidation with other supposedly inert materials, like crystalline silica (sea sand), amorphous fumed silica (Aerosil 380), and silicon carbide (Extended Data Tab. 1). The specific surfaces and pore volumes of the materials vary over a wide range. All materials contain trace impurities of transition metal and main group elements, but the concentration is very low and differs from material to material.

The conversion of propane under the same reaction conditions is different (Fig. 1), but, unexpectedly, all materials show identical product selectivity. We also surprisingly discovered that a mixture of propylene and propylene oxide (two valuable products) formed above the apparently inert materials.

Interestingly, the formation of propylene oxide has never been reported in studies of propane oxidation with molecular oxygen over either redox-active selective oxidation catalysts or nitrides and carbides, although it is well known that PO and numerous other intermediates are part of the reaction network in the low-temperature $\left(<630^{\circ} \mathrm{C}\right)$ ignition chemistry of hydrocarbons in the homogeneous gas phase, 
which involve peroxy and hydroperoxy radical species. ${ }^{19-21}$ In a very similar way, hydrogen peroxide was obtained in quite high yields in propane oxidation at $430-450^{\circ} \mathrm{C}$ in empty steel reactors together with propylene, formaldehyde, acetaldehyde, methanol, and propylene oxide. ${ }^{22}$ There is, however, a report on the formation of propylene oxide in propane oxidation at temperatures between 400 und $430^{\circ} \mathrm{C}$ on $\mathrm{SiO}_{2}$-supported $\mathrm{V}_{2} \mathrm{O}_{5}$ catalysts. ${ }^{23}$ But in this case, $\mathrm{N}_{2} \mathrm{O}$ was used as oxidant, instead of molecular oxygen. The process condition and the filling materials applied in the present study apparently allow the stabilization of propylene oxide, which is an instable intermediate in total oxidation of propane in presence of oxygen on redox-active catalysts.

Propylene, propylene oxide, ethylene, and $\mathrm{CO}$ are the main products in the parameter space investigated, while $\mathrm{CO}_{2}$, acetaldehyde, acrolein, and propionaldehyde are formed in negligible amounts (Fig. 1 and Extended Data Fig. 1). When propylene oxide forms, the oxygen concentration in the gas phase is not zero (Fig. 1d). The similarity in the product distribution over all apparently inert substances indicates that the reaction network is identical in all experiments. Differences between the different filling materials can only be observed with regard to the propane conversion, which could be attributed to different heat transfer properties of the materials. A very similar observation was made by Hermans and co-workers in their investigation of boron-containing catalysts, such as boron carbide, titanium boride, nickel boride, cobalt boride, hafnium boride, and tungsten boride and elemental boron, however, without the formation of propylene oxide being reported. ${ }^{24}$ In this work and numerous other studies, surfacestabilized $\mathrm{BO}_{\mathrm{x}}$ species have been thought to be the active sites in a catalysed reaction at the solid-gas interphase.

The apparent activation energies $E_{a}$ are much higher than those measured for vanadium oxide catalysts. The latter have been studied most frequently in propane oxidation, where the activation energies determined range from 40 to $170 \mathrm{~kJ} / \mathrm{mol}$ (Extended Data Tab. 2). ${ }^{25}$ The data from our study are consistent with the values measured previously in concentrated feeds over boron nitride. ${ }^{14,26}$ In oxygen-rich feed, on the other hand, values around $190 \mathrm{~kJ} / \mathrm{mol}$ were found..$^{27-29}$ The observations made by Loilad et al. led 
to the conclusion that the catalysts seem to initiate the formation of radicals on their surfaces under nondilute conditions, which then desorb into the gas phase to undergo radical chain reactions. ${ }^{26}$ The contribution of radical reactions to the reaction mechanism via boron-containing catalysts has since been increasingly discussed. ${ }^{30-32}$

In Addition to the unusual high $E_{a}$, very high reaction orders with regard to propane of 2.3 for $h$-BN and 2.8 for $\mathrm{SiO}_{2}$ were measured. This means that the rate of the reaction strongly depends on the concentration of propane in the gas phase. In contrast, values of $<1$ are frequently determined in propane oxidation over vanadium oxide-containing catalysts. ${ }^{33}$ The partial pressure of oxygen has only a little influence on the rate, similar to redox-active catalysts (reaction orders 0.4 for $h$ - $\mathrm{BN}$ and 0.3 for $\mathrm{SiO}_{2}$ ). ${ }^{33}$

An increase in the propane concentration causes an increase in the integral formation rates of propylene oxide and ethylene (Extended Data Figs. 1-2). The formation of $\mathrm{CO}$ and $\mathrm{CO}_{2}$ is hardly affected (Extended Data Fig. 1). The results show that a higher concentration of propane is needed to reach a higher PO selectivity.

The propane conversion increases with increasing layer height of the material, but there is no linear relationship (Extended Data Fig. 3). A limitation of the reaction rate by film diffusion can be excluded in the present experiments (Extended Data Fig. 3). Furthermore, rate limitations due to pore diffusion are considered unlikely due to the non-microporous nature of the analyzed materials. These results clearly indicate that the surface of the different materials is not directly catalysing the reaction. 


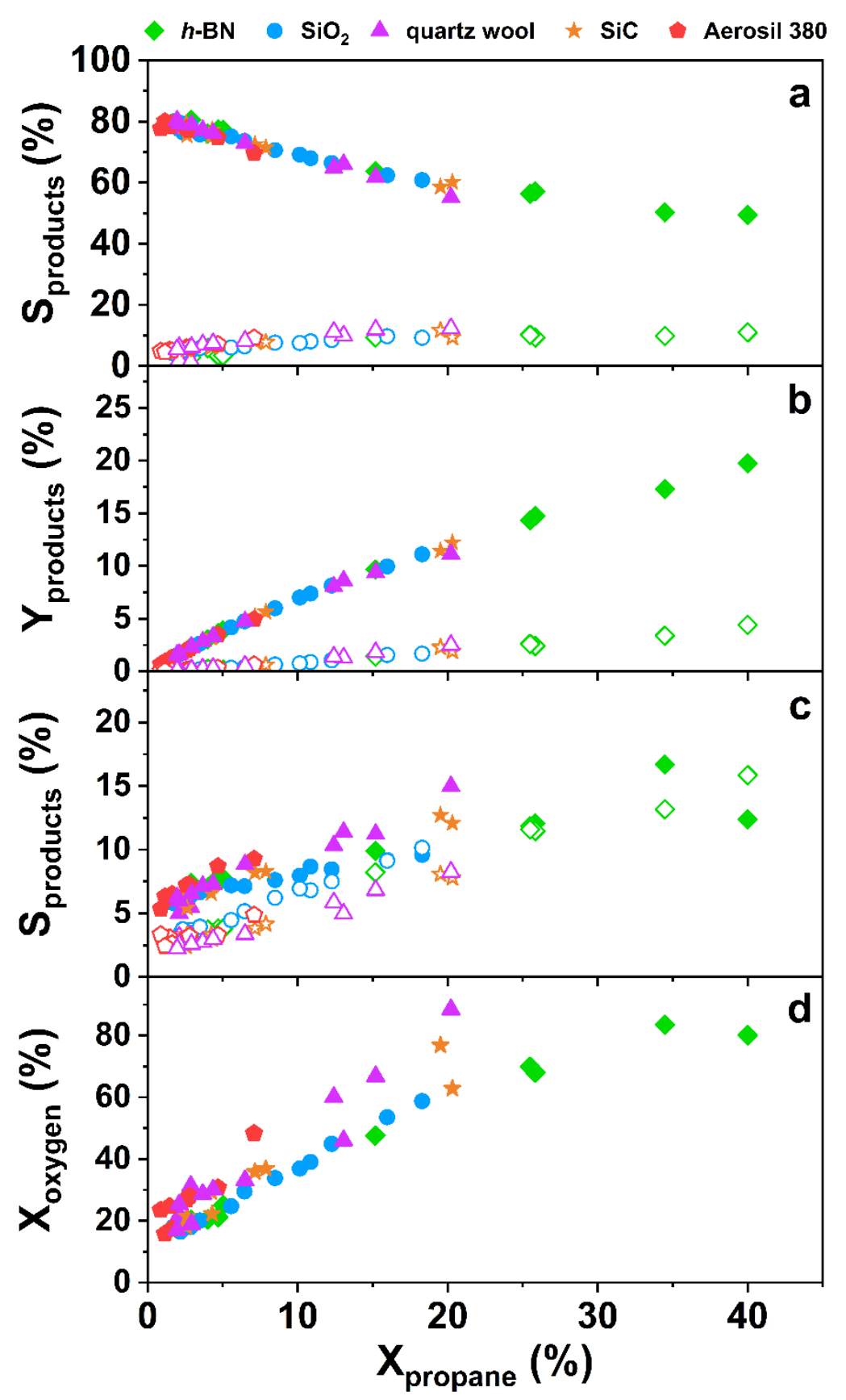

Fig. 1: Performance of propane oxidation using various filling materials in the reactor.

a, Selectivity and b, yield of propylene (filled symbols) and propylene oxide (open symbols); c, selectivity to ethylene (filled symbols) and $\mathrm{CO}$ (open symbols), and $\mathbf{d}$, conversion of $\mathrm{O}_{2}$ shown as a function of propane conversion; The data are measured in a tubular fixed bed reactor with the following reaction conditions: Temperature $\left(470^{\circ} \mathrm{C}\right.$ to $\left.510^{\circ} \mathrm{C}\right)$, feed $\left(\mathrm{C}_{3} \mathrm{H}_{8} / \mathrm{O}_{2} / \mathrm{He}=30 / 15 / 55\right)$, flow rate $(3.3$ to $20 \mathrm{ml} / \mathrm{min})$, mass was 0.188 and $0.376 \mathrm{~g}$ for $h$ - $\mathrm{BN}, 0.3,0.6$, and $1.0 \mathrm{~g}$ for $\mathrm{SiO}_{2}, 0.5 \mathrm{~g}$ for $\mathrm{SiC}$, and $0.051 \mathrm{~g}$ for Aerosil 380 . 


\section{Temperature-programmed experiments}

Our observation that $\mathrm{SiO}_{2}, \mathrm{SiC}$, Aerosil 380 and a reactor filled with quartz wool show very good performance in the propane oxidation (Fig.1), similar to published boron-containing materials, although propylene oxide formation was also observed for the first time in the present work, suggests that gasphase reactions are taking place instead of surface catalysed reactions. ${ }^{19-21,31,34}$ The kinetics of elementary reactions in low-temperature autoignition chemistry of alkanes have been reviewed by Zador $e t$ $a l .{ }^{21}$ Kinetic models for the ignition and combustion of propane in air and for the oxidation of propylene in the gas phase can be found in the literature, e.g., by Titova et al. and Wilk et al. ${ }^{34,35}$ Basically, all the intermediates observed in the present work can be explained by reactions that are part of the extensive and complex reaction networks proposed in the combustion chemistry of propane in the gas phase. ${ }^{21,34-36}$ To verify whether gas phase processes dominate in our case, temperature-programmed experiments were carried out in which the gas formed was analysed by mass spectrometry (Fig. 2).

The reaction conditions chosen in the temperature-programmed experiment correspond in part to the conditions that have also been used in the literature when investigating boron-containing catalysts. The gas composition does not change over a wide temperature range $\left(350^{\circ} \mathrm{C}\right.$ to approx. $\left.470{ }^{\circ} \mathrm{C}\right)$. At a temperature of about $470^{\circ} \mathrm{C}$, however, propylene suddenly appears (increase of $\mathrm{m} / \mathrm{z} 42$ ), while propane is consumed at the same time (decrease of $\mathrm{m} / \mathrm{z} 44$ ). After the reaction reaches its full extent, products such as water and propylene oxide are observed as molecular ion peaks (increase in $\mathrm{m} / \mathrm{z}$ of 18 and 58 , respectively). At the same time, an increased intensity is observed in the $\mathrm{m} / \mathrm{z}$ range from 25 to 27 , which could be attributed to the formation of ethylene or molecular fragments of the propylene formed. The consumption of oxygen can be clearly seen in the decreasing intensity of $\mathrm{m} / \mathrm{z} 32$.

The course of the reaction definitely speaks for an ignition of the propane-oxygen reaction mixture, which triggers the corresponding gas phase reactions. The ignition of alkane-oxygen mixtures on noble metal catalysts has been intensively studied mainly with regard to partial oxidation to synthesis gas, concluding that the surface mediates the ignition. ${ }^{37-40}$ The ignition behaviour differs only slightly when 
boron nitride is filled into the reactor instead of $\mathrm{SiO}_{2}$ (Extended Data Fig. 4) and it can be controlled via the reaction conditions, such as the heating rate (Extended Data Fig. 5). Filling the reactor with an inert material apparently supports gas mixing and heat transport, but is not absolutely necessary for product formation (Extended Data Fig. 6). It is important here that there is no redox-active catalyst in the reactor, which can lead to subsequent reactions of less stable products, such as propylene oxide, with the oxygen that is still present (Fig. $1 \mathrm{~d}$ ) and thus to the total oxidation of valuable products to $\mathrm{CO}_{2}$. The gasphase oxygen itself is essential for the initiation and propagation of the radical chain reactions that lead to the valuable products.

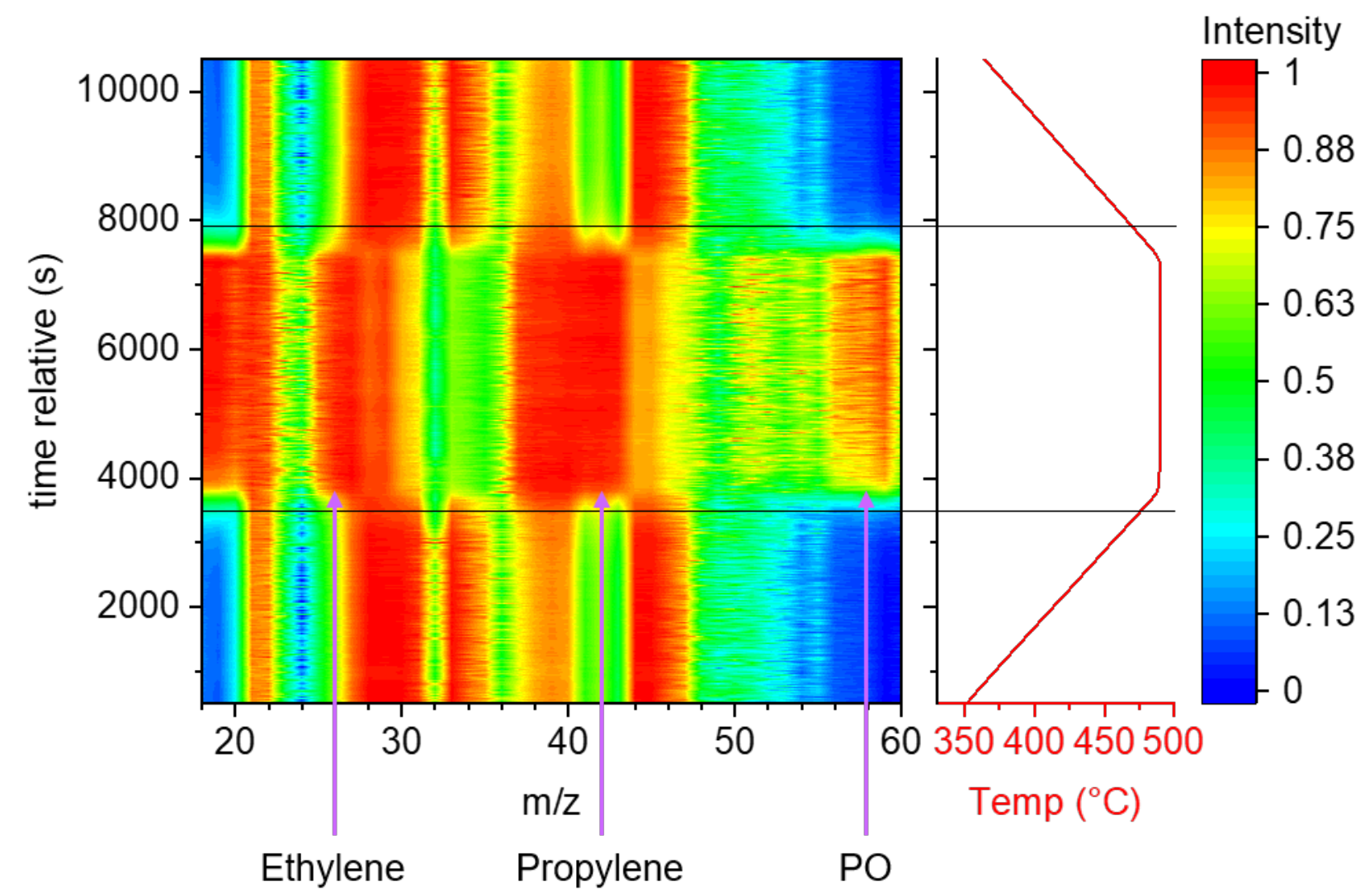

Fig. 2: Temperature programmed oxidation of propane using $\mathrm{SiO}_{2}$ as filler.

Temperature range: $350{ }^{\circ} \mathrm{C}$ to $490{ }^{\circ} \mathrm{C}$; Mass-to-charge ratios $\mathrm{m} / \mathrm{z} 18$ to 60 were recorded; Total flow $=$ $10 \mathrm{ml} \mathrm{min}{ }^{-1}, \mathrm{~m}=670 \mathrm{mg}$; Feed $\left(\mathrm{C}_{3} \mathrm{H}_{8} / \mathrm{O}_{2} / \mathrm{He}\right)=30 / 15 / 55$; Heating rate $2.5 \mathrm{~K} \mathrm{~min}^{-1}$. 


\section{Economic efficiency assessment}

In summary, unexpectedly high yields of propylene (20\%) and propylene oxide (4.4\%) can be achieved in a propane rich feed (30\% propane or higher and 15\% oxygen) (Fig. 1) at a reaction temperature of $490^{\circ} \mathrm{C}$. The economic viability of a hypothetical one-step process was estimated using Aspen HYSYS (Extended Data Fig. 7). Fig. 3 shows the flowchart of the direct process (40\% propane conversion at $490{ }^{\circ} \mathrm{C}$ and 1 bar, $11 \%$ propylene oxide selectivity), which is the basis for the Aspen simulation model, in comparison with three common current processes for manufacturing of propylene oxide under the assumption that these also start from propane in order to enable a holistic view.

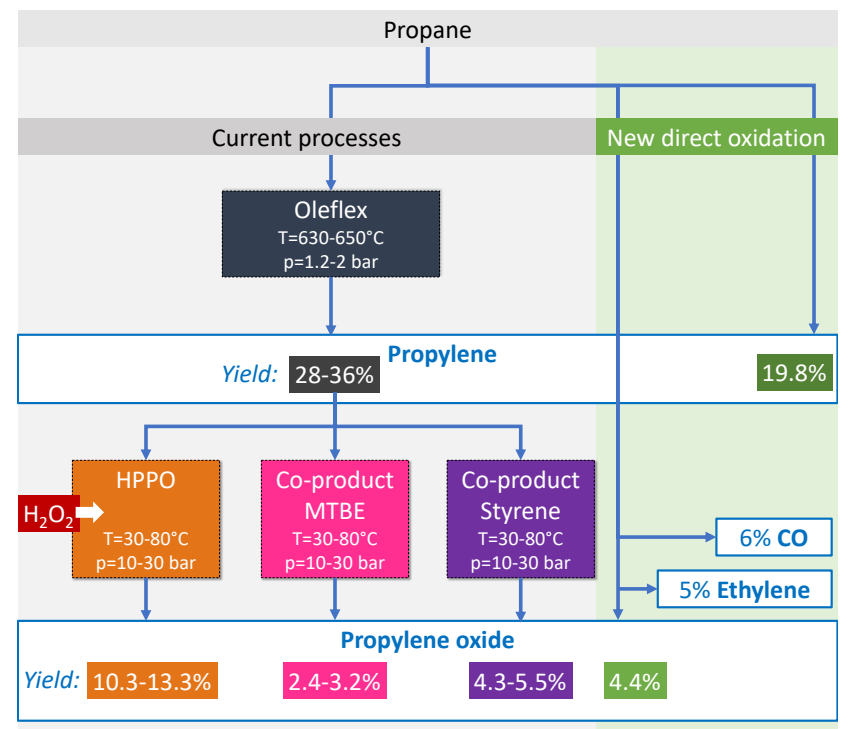

Fig. 3: Comparison of the yields of a direct propane oxidation route compared to established processes.

The calculation of the yield of valuable products was based on the same C3 source (propane). The established processes are based on propylene, which is previously produced by cracking petroleum fractions. Expensive additives and reactants such as $\mathrm{H}_{2} \mathrm{O}_{2}$ or solvents are also used. For a direct comparison, it was assumed that propane, as found in natural gas, is also used for the established processes. ${ }^{9}$ The calculation of the yield illustrates the sustainability of the direct oxidation route with regard to the utilisation of the carbon source. However, the decisive factor for the economic viability of the new direct oxidation process is the sales price of PO simulated for it (see text). 
Valuable products, as produced directly from propane in such a direct process could be sold for the following hypothetical prices: propylene $1048 \$ /$ ton, ${ }^{41}$ propylene oxide $2689 \$ /$ ton, ${ }^{42}$ hydrogen $6 \$ /$ ton, ${ }^{43}$ and acetaldehyde $973 \$ /$ ton. ${ }^{44}$ These prices are close to the current market prices. It should be mentioned here that the cost / economic estimation can be optimized to represent industrial conditions. Possible parameters for optimization are the utilization of process heat, the use of air instead of a helium-oxygenmixture as feed gas, which was used under our laboratory conditions, and the optimization of the distillation columns.

The direct process from propane to propylene and propylene oxide therefore definitely has potential for industrial application. The process would be absolutely green if the energy supply is provided by electrical renewable energy, because hardly any climate-damaging $\mathrm{CO}_{2}$ is produced as a by-product. In our experiments, the ignition of the propane-rich reaction mixture at about $470{ }^{\circ} \mathrm{C}$ was crucial for the formation of products that can easily be further oxidised. This teaches us that we can produce thermodynamically less stable, oxidation-sensitive products in oxidation reactions if we set conditions for fast radical reactions and omit the catalyst. The knowledge gained is of far-reaching importance for research in oxidation catalysis, as many catalysts are investigated in this temperature range. Reaction mechanisms assuming surface reactions, as proposed for boron oxides, can be ruled out. ${ }^{14,45}$ Redox-active catalysts that give rise to activated oxygen species on their surface are against a long tradition of searching for selective complex interfaces rather inappropriate for the formation of sensitive reaction products, such as propylene oxide. The thermodynamically limited activation of di-oxygen to only superoxide and the fast sorption-desorption kinetics are success factors. Efforts to control the oxidative potential of atomic oxygen species, which can only form at surface defects, are less successful, possibly because the required high selectivity demands high sorption specificity and thus long residence times on the surface, leading to further combustion of the valuable reaction products. 


\section{Methods}

\section{Materials and Gases}

All used materials are commercially available and were ordered from the following companies: $\mathrm{SiO}_{2}$ (Quartz) from Supelco (puriss p.a., Lot number SZBA0210), hexagonal boron nitride ( $h$-BN) from Alfa Aesar (Quality 99.5 \%, Lot number E31M55), Aerosil 380 from Evonik (Lot number 157012015), and silicon carbide ( $\mathrm{SiC}$ ) from ESK-SiC GmbH (Lot number 654508). The gases propane (purity 99.95 \%), oxygen (purity $99.999 \%$ ), helium (purity $99.999 \%$ ) and nitrogen (purity 99.999\%) were supplied by Westfalen company.

\section{Characterization of Materials}

Nitrogen adsorption was performed at $-196^{\circ} \mathrm{C}$ using the Autosorb-6B analyser (Quantachrome) after outgassing the catalysts in vacuum $\left(\mathrm{SiO}_{2}\right.$ and $h$-BN for $2 \mathrm{~h}$ at $200{ }^{\circ} \mathrm{C}$, Aerosil 380 for $12 \mathrm{~h}$ at $200^{\circ} \mathrm{C}, \mathrm{SiC}$ for $2 \mathrm{~h}$ at $300^{\circ} \mathrm{C}$ ). All data treatments were performed using the Quantachrome Autosorb software package. The specific surface area $S_{B E T}$ was calculated according to the multipoint Brunauer-Emmett-Teller method (BET) in the $\mathrm{p} / \mathrm{p}_{0}=0.05-0.15$ pressure range assuming the $\mathrm{N}_{2}$ cross sectional area of $16.2 \AA^{2}$. X-ray fluorescence spectroscopy (XRF) was used for elemental analysis applying a Bruker S4 Pioneer X-ray spectrometer. For sample preparation, the mixture of $0.1 \mathrm{~g}$ of the material and $8.9 \mathrm{~g}$ of lithium tetraborate ( $>99.995 \%$, Aldrich) was fused into a disk using an automated fusion machine (Vulcan 2 MA, Fluxana).

Inductively coupled plasma optical emission spectrometry (ICP-OES) was used as a second technique for elemental analysis. An Optima 8300 from Perkin Elmer with Zyklon nebulizer was used in axial mode. Minimum two points calibration with forced intercept at zero were measured with certified standards. Peak evaluation is based on three points per peak. Water was used as spectral blank. Dissolution of the samples was done in a multiwave Pro autoclave from Anton Paar, equipped with teflon liner at 200 
${ }^{\circ} \mathrm{C}$ and 60 bar. Reagents in supra pure quality and water from an ELGA pure water system (VEOLIA) (conductivity $0.05 \mu \mathrm{S} / \mathrm{cm}$ ) were used.

Phase analysis was performed by X-ray diffraction (XRD) using a Bruker D8 ADVANCE diffractometer ( $\mathrm{Cu} \mathrm{K \alpha}$ radiation, secondary graphite monochromator, scintillation counter).

\section{Propane oxidation}

The propane oxidation experiments were carried out in a self-built reactor with plug flow characteristics. All measurements were performed at atmospheric pressure and the pressure in the reactor was monitored with pressure sensors upstream and downstream of the reactor tube. The following general reaction conditions were applied: Mass of material from 100 to $1500 \mathrm{mg}$, temperature from $470{ }^{\circ} \mathrm{C}$ to 510

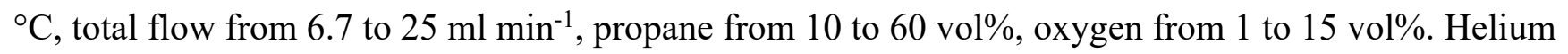
was used as balance. A certain amount of material (sieve fraction from 250 to $355 \mu \mathrm{m}$ ) was filled into the quartz reactor (inner diameter $7 \mathrm{~mm}$ ) without dilution or the empty reactor was used. The gas hourly space velocity (GHSV), $\left[\mathrm{h}^{-1}\right]$ was calculated using the bulk volume of the material in the reactor and the applied volumetric gas flow at standard conditions $(\mathrm{T}=273.15 \mathrm{~K}$ and $\mathrm{p}=0.1013 \mathrm{MPa})$ according to the following formula:

$$
G H S V=\frac{V_{\text {gas }}^{\cdot}}{V_{\text {material }}}
$$

The product gas mixtures were analysed by online gas chromatography (Agilent 7890 GC). The following GC column combinations were used for product analysis: 1.) Plot-Q (length $30 \mathrm{~m}, 0.53 \mathrm{~mm}$ internal diameter, $40 \mu \mathrm{m}$ film thickness) plus Plot-MoleSieve 5 A (30 m length, $0.53 \mathrm{~mm}$ internal diameter, 50 $\mu \mathrm{m}$ film thickness), connected to a thermal conductivity detector (TCD) for analysis of the permanent gases $\left(\mathrm{CO}, \mathrm{CO}_{2}\right.$, and $\left.\mathrm{O}_{2}\right)$ and 2.) Plot-Q (length $30 \mathrm{~m}, 0.53 \mathrm{~mm}$ internal diameter, $40 \mu \mathrm{m}$ film thickness) plus FFAP (length $30 \mathrm{~m}, 0.53 \mathrm{~mm}$ internal diameter, $1 \mu \mathrm{m}$ film thickness) connected to a flame ionization detector (FID) for analysis of hydrocarbons and oxygenates. 
The calculation of the propane conversion $\left(X_{\text {propane }}\right)$ and selectivity $\left(S_{i}\right)$ of product $\mathrm{i}$ in percentage, were done based on the carbon number and the sum of all products using the following formulas:

$$
\begin{gathered}
X_{C_{3} H_{8}}=\frac{\sum_{i=1}^{n} N_{i} c_{i}}{\sum_{i=1}^{n} N_{i} c_{i}+3 c_{C_{3} H_{8}, \text { out }}} \cdot 100 \\
S_{i}=\frac{N_{i} c_{i}}{\sum_{i=1}^{n} N_{i} c_{i}} \cdot 100
\end{gathered}
$$

$N_{i}$ is the number of carbon atoms in product $\mathrm{i}, c_{i}$ is the concentration of product $\mathrm{i}$ at the reactor outlet, and $c_{C_{3} H_{8} \text { out }}$ is the propane concentration in the outlet gas.

The oxygen conversion was calculated using the following formula, where $c_{O_{2}, \text { in }}$ and $c_{O_{2} \text {,out }}$ are the concentrations of the oxygen in the feed gas at inlet and outlet position, respectively, of the reactor.

$$
X_{O_{2}}=\frac{c_{O_{2}, \text { in }}-c_{O_{2}, \text { out }}}{c_{O_{2}, \text { in }}} \cdot 100
$$

The yield $\left(Y_{\mathrm{i}}\right)$ of product $\mathrm{i}$ in percentage was calculated by using the following formula:

$$
Y_{i}=\frac{X_{C_{3} H_{8}} \cdot S_{i}}{100}
$$

The carbon balance $\left(C_{\text {balance }}\right)$ was determined as follows:

$$
C_{\text {balance }}=\frac{\sum_{i=1}^{n} N_{i} c_{i}+3 c_{C_{3} H_{8}, \text { out }}}{3 c_{C_{3} H_{8}, \text { in }}} \cdot 100
$$

In all experiments, the carbon balance was $100 \%+/-5 \%$. The formation of polymerization products was not observed.

Reaction rates $r_{i}$ for propane consumption, propylene formation and propylene oxide formation in mol $\mathrm{g}^{-1} \mathrm{~h}^{-1}$ were calculated using the following formula:

$$
r_{i}=\frac{d n_{\mathrm{i}}}{d\left(\frac{W}{F}\right)}
$$


The amount of starting compound $\mathrm{i}$ consumed or product $\mathrm{i}$ formed $\left(n_{i}\right)$ was used in the unit mol $\mathrm{ml}^{-1} . W$ is the mass of the material in $\mathrm{g}$ and $F$ is the total flow rate in $\mathrm{ml} \mathrm{min}^{-1}$.

Mass transfer limitations were excluded by measuring the propane conversion when using different amounts of material and different gas flows (see Figure S7) and checked by calculating the dimensionless Mears and Weisz-Prater criteria. $\mathrm{SiO}_{2}$ has the highest Mears modulus of $5.7 \cdot 10^{-6}$ (must be $<1.8^{8} \cdot 10^{-}$ ${ }^{2}$ ) and Weisz-Prater modulus of $2.24 \cdot 10^{-3}$ (must be $<0.07$ ) for measurements at $490^{\circ} \mathrm{C}$ of all materials tested, indicating that mass transport limitations do not play a role.

\section{Temperature-programmed experiments}

The experiments were performed in the same reactor setup, which was described in the previous section. An online mass spectrometer (QMA 400, Pfeiffer Vacuum) was used for recording the reactant and product gas streams. $670 \mathrm{mg}$ of $\mathrm{SiO}_{2}$ and $665 \mathrm{mg}$ of $h-\mathrm{BN}$, respectively, were loaded into the reactor. A total flow of $10 \mathrm{ml} / \mathrm{min}$, which was composed of $30 \%$ propane, $15 \%$ oxygen and $55 \%$ helium, was used. First, the reactor was heated up to $350^{\circ} \mathrm{C}$ with a heating rate of $5 \mathrm{~K} \mathrm{~min}^{-1}$ and hold at this temperature for minimum 15 minutes. Then the temperature-programmed experiment was performed by heating up to $490^{\circ} \mathrm{C}$ with a heating rate of $2.5 \mathrm{~K} \mathrm{~min}^{-1}$ or $5 \mathrm{~K} \mathrm{~min}^{-1}$, respectively, holding at $490{ }^{\circ} \mathrm{C}$ for 1 hour and then cooling down with the same rate like for heating up.

The reaction gas was withdrawn approximately $5 \mathrm{~cm}$ behind the material bed by using a capillary-vacuum pump combination and fed into the mass spectrometer (QMA 400, Pfeiffer Vacuum). All m/z from 18 to 60 were monitored simultaneously with a scanning rate of $50 \mathrm{~ms} \mathrm{per} \mathrm{m/z.}$

\section{Data availability}

The data that support the findings of this study are stored on the internal FHI AC/CATLAB Archive (https://ac.archive.fhi.mpg.de/login), ID P51468, and public access is enabled after publication. 


\section{References}

1 Kätelhön, A., Meys, R., Deutz, S., Suh, S. \& Bardow, A. Climate change mitigation potential of carbon capture and utilization in the chemical industry. Proc. Natl. Acad.Sci. U.S.A. 116, 11187-11194, (2019).

2 The European Green Deal in COMMUNICATION FROM THE COMMISSION TO THE EUROPEAN PARLIAMENT, THE EUROPEAN COUNCIL, THE COUNCIL, THE EUROPEAN ECONOMIC AND SOCIAL COMMITTEE AND THE COMMITTEE OF THE REGIONS (Eurepean Comission, Brussels, 2019).

3 Mitchell, S., Qin, R., Zheng, N. \& Pérez-Ramírez, J. Nanoscale engineering of catalytic materials for sustainable technologies. Nat. Nanotechnol. 16, 129-139, (2021).

4 Studer, A. \& Curran, D. P. Catalysis of Radical Reactions: A Radical Chemistry Perspective. Angew. Chem. Int. Ed. 55, 58-102, (2016).

5 Alabdullah, M. et al. One-step conversion of crude oil to light olefins using a multi-zone reactor. Nat. Catal. 4, 233-241,(2021).

6 Skylaris, C.-K. A benchmark for materials simulation. Science 351, 1394-1395, (2016).

7 Kitchin, J. R. Machine learning in catalysis. Nat. Catal. 1, 230-232, (2018).

8 Zhao, Z., Jiang, J. \& Wang, F. An economic analysis of twenty light olefin production pathways. J. Energy Chem. 56, 193-202, (2021).

9 Baer, H., Bergamo, M., Forlin, A., Pottenger, L. H. \& Lindner, J. Propylene Oxide. (Wiley Online Library, 2012).

10 Gordon, C. P. et al. Efficient epoxidation over dinuclear sites in titanium silicalite-1. Nature 586, 708-713, (2020).

11 Khatib, S. J. \& Oyama, S. T. Direct Oxidation of Propylene to Propylene Oxide with Molecular Oxygen: A Review. Catal. Rev. 57, 306-344, (2015).

12 Marimuthu, A., Zhang, J. \& Linic, S. Tuning Selectivity in Propylene Epoxidation by Plasmon Mediated Photo-Switching of Cu Oxidation State. Science 339, 1590-1593, (2013).

13 Lei, Y. et al. Increased Silver Activity for Direct Propylene Epoxidation via Subnanometer Size Effects. Science 328, 224-228, (2010).

14 Grant, J. T. et al. Selective oxidative dehydrogenation of propane to propene using boron nitride catalysts. Science 354, 1570-1573, (2016).

15 Goyal, R. et al. Single-step synthesis of hierarchical $\mathrm{B}_{\mathrm{x}} \mathrm{CN}$ : a metal-free catalyst for lowtemperature oxidative dehydrogenation of propane. J. Mater. Chem. A 4, 18559-18569, (2016).

16 Venegas, J. M. et al. Selective Oxidation of n-Butane and Isobutane Catalyzed by Boron Nitride. ChemCatChem 9, 2118-2127, (2017).

17 Huang, R. et al. Direct Insight into Ethane Oxidative Dehydrogenation over Boron Nitrides. ChemCatChem 9, 3293-3297, (2017).

18 Fang, Y. \& Wang, X. Metal-Free Boron-Containing Heterogeneous Catalysts. Angew. Chem. Int. Ed. 56, 15506-15518, (2017).

19 Goldsmith, C. F., Green, W. H. \& Klippenstein, S. J. Role of $\mathrm{O}_{2}+$ QOOH in Low-Temperature Ignition of Propane. 1. Temperature and Pressure Dependent Rate Coefficients. J. Phys. Chem. A 116, 3325-3346, (2012).

20 Merchant, S. S. et al. Understanding low-temperature first-stage ignition delay: Propane. Combust. Flame 162, 3658-3673, (2015).

21 Zador, J., Taatjes, C. A. \& Fernandes, R. X. Kinetics of elementary reactions in low-temperature autoignition chemistry. Prog. Energy Combust. Sci. 37, 371-421, (2011).

22 Kunugi, T., Ikeda, M., Miyako, T.\& Matsuura, T. Kinetic Study of Formation of Hydrogen Peroxide by Vapor-Phase Noncatalytic Oxidative Dehydrogenation of Propane. Adv. Chem. Ser., 326-\&, (1968). 
23 Held, A., Kowalska-Kus, J. \& Nowinska, K. Propane-to-propene oxide oxidation on silicasupported vanadium catalysts with $\mathrm{N} 2 \mathrm{O}$ as an oxidant. J. Catal. 336, 23-32, (2016).

24 Grant, J. T. et al. Boron and Boron-Containing Catalysts for the Oxidative Dehydrogenation of Propane. ChemCatChem 9, 3623-3626, (2017).

25 Carrero, C. A., Schlögl, R., Wachs, I. E. \& Schomaecker, R. Critical Literature Review of the Kinetics for the Oxidative Dehydrogenation of Propane over Well-Defined Supported Vanadium Oxide Catalysts. ACS Catal. 4, 3357-3380, (2014).

26 Loiland, J. A., Zhao, Z., Patel, A. \& Hazin, P. Boron-Containing Catalysts for the Oxidative Dehydrogenation of Ethane/Propane Mixtures. Ind. Eng. Chem. Res. 58, 2170-2180, (2019).

27 Shi, L. et al. Edge-hydroxylated Boron Nitride for Oxidative Dehydrogenation of Propane to Propylene. ChemCatChem 9, 1788-1793, (2017).

28 Tian, J. S. et al. Hexagonal boron nitride catalyst in a fixed-bed reactor for exothermic propane oxidation dehydrogenation. Chem. Eng. Sci. 186, 142-151, (2018).

29 Chen, J. J. et al. Boron-hyperdoped silicon for the selective oxidative dehydrogenation of propane to propylene. Chem. Commun. 56, 9882-9885, (2020).

30 Venegas, J. M. et al. Why Boron Nitride is such a Selective Catalyst for the Oxidative Dehydrogenation of Propane. Angew. Chem. Int. Ed. 59, 16527-16535, (2020).

31 Kraus, P. \& Lindstedt, R. P. It's a Gas: Oxidative Dehydrogenation of Propane over Boron Nitride Catalysts. J. Phys. Chem. C 125, 5623-5634, (2021).

32 Zhang, X. et al. Radical Chemistry and Reaction Mechanisms of Propane Oxidative Dehydrogenation over Hexagonal Boron Nitride Catalysts. Angew. Chem. Int. Ed. 59, 80428046, (2020).

33 Kube, P. et al. Functional Analysis of Catalysts for Lower Alkane Oxidation. ChemCatChem 9 , 573-585, (2017).

34 Wilk, R. D., Cernansky, N. P., Pitz, W. J. \& Westbrook, C. K. Propene Oxidation at Low and Intermediate Temperatures - a Detailed Chemical Kinetic-Study. Combust. Flame 77, 145-170, (1989).

35 Titova, N. S., Kuleshov, P. S. \& Starik, A. M. Kinetic mechanism of propane ignition and combustion in air. Combust. Explos. Shock Waves 47, 249-264, (2011).

36 Lifshitz, A. \& Tamburu, C. Isomerization and Decomposition of Propylene-Oxide-Studies with a Single-Pulse Shock-Tube. J. Phys. Chem. C 98, 1161-1170, (1994).

37 Veser, G., Ziauddin, M. \& Schmidt, L. D. Ignition in alkane oxidation on noble-metal catalysts. Catal. Today 47, 219-228, (1999).

38 Huff, M. \& Schmidt, L. D. Ethylene formation by oxidative dehydrogenation of ethane over monoliths at very short contact times. J. Phys. Chem. C 97, 11815-11822, (1993).

39 Iordanoglou, D. I., Bodke, A. S. \& Schmidt, L. D. Oxygenates and Olefins from Alkanes in a Single-Gauze Reactor at Short Contact Times. J. Catal. 187, 400-409, (1999).

40 A. Henning, D. \& D. Schmidt, L. Oxidative dehydrogenation of ethane at short contact times: species and temperature profiles within and after the catalyst. Chem. Eng. Sci. 57, 2615-2625, (2002).

41 Price of propylene in 2021 https://www.statista.com/statistics/1170576/price-propylene-forecastglobally/ (2021).

42 Price of propylene oxide from 30.04.2021 http://www.sunsirs.com/uk/prodetail-438.html (2021).

43 Deloitte-Ballard Joint White Paper Assesses Hydrogen \& Fuel Cell Solutions for Transportation https://www2.deloitte.com/content/dam/Deloitte/cn/Documents/finance/deloitte-cn-fueling-thefuture-of-mobility-en-200101.pdf (2020).

$44 \quad$ Price of acetaldehyde from 25.12.2018 https://www.echemi.com/productsInformation/pid_Rock16660-acetaldehyde.html (2018).

45 Zhou, H. et al. Isolated boron in zeolite for oxidative dehydrogenation of propane. Science 372, 76-80, (2021). 


\section{Acknowledgements}

The authors thank Maike Hashagen for measuring the specific surface areas of the investigated materials, Dr. Frank Girgsdies for X-ray diffraction analysis and Dr. Olaf Timpe for chemical analysis.

\section{Author information}

\section{Affiliations}

Fritz-Haber-Institut der Max-Planck-Gesellschaft, Department of Inorganic Chemistry, Faradayweg 4-6, 14195 Berlin, Germany

Pierre Kube, Jinhu Dong, Toyin Omojola, Robert Schlögl \& Annette Trunschke

Max-Planck-Institut für Chemische Energiekonversion, Department of Heterogeneous Reactions, Stiftstrasse 34-36, 45470 Mülheim an der Ruhr, Germany

Nuria Sánchez Bastardo, Holger Ruland \& Robert Schlögl

\section{Contributions}

Pierre Kube performed the propane oxidation and the temperature-programmed experiments and analyzed the data. He also contributed to the design of the experiments. Jinhu Dong performed a part of the experiments, contributed to the discussion, and provided support for data analysis. Toyin Omojola, $\mathrm{Nu}$ ria Sánchez Bastardo, and Holger Ruland carried out the economic feasibility study. Robert Schlögl contributed in the discussion, data interpretation, concepts of experiments, and writing. The work was conceptually supervised by Annette Trunschke, who also has written the manuscript.

\section{Corresponding author}

Correspondence to Annette Trunschke (https://orcid.org/0000-0003-2869-0181)

Fritz-Haber-Institut der Max-Planck-Gesellschaft, Department of Inorganic Chemistry, Faradayweg 4-6, 14195 Berlin (Germany) 
trunschke@fhi-berlin.mpg.de

\section{Ethics declarations}

\section{Competing interests}

The authors declare no competing interests.

\section{Additional information}


Extended data figures and tables

Extended Data Tab. 1: Properties of the materials filled into the reactor.

\begin{tabular}{ccccc}
\hline & $\begin{array}{c}S_{B E T} \\
\left(\mathrm{~m}^{2} \mathrm{~g}^{-1}\right)\end{array}$ & $\begin{array}{c}V_{p} \\
\left(\mathrm{~cm}^{3} \mathrm{~g}^{-1}\right)\end{array}$ & $\begin{array}{c}\text { Impurities } \\
(\text { wt-\% })\end{array}$ & $\begin{array}{c}\text { Phase } \\
\text { composition }\end{array}$ \\
\cline { 2 - 5 } $\mathrm{SiO}_{2}$ & 1.6 & 0.0004 & $\begin{array}{c}0.014 \mathrm{Ti} \\
0.003 \mathrm{Mn}\end{array}$ & $\alpha$-quartz \\
Aerosil 380 & 394 & 1.8 & - & Amorphous \\
$\mathrm{SiC}$ & 0.1 & 0.0006 & $0.007 \mathrm{Ti}$ & $\begin{array}{c}\text { mixture of various SiC polytypes } \\
\text { main component: moissanite-6H }\end{array}$ \\
& & & $0.002 \mathrm{Mn}$ & \\
$h$-BN & 9.0 & 0.005 & $0.4 \mathrm{Si}$ & Hexagonal \\
& & & $0.2 \mathrm{Zr}$ & \\
& & & $(0.04) \mathrm{Cr}$ &
\end{tabular}

Extended Data Tab. 2: Apparent activation energies measured for different feed compositions.

\begin{tabular}{|c|c|c|}
\hline & $\begin{array}{l}E_{a, \text { propane }} \\
\left(\mathrm{kJ} \mathrm{mol}^{-1}\right)\end{array}$ & $\begin{array}{l}\text { Feed composition } \\
\left(\mathrm{C}_{3} \mathrm{H}_{8} / \mathrm{O}_{2} / \text { Inert }\right)\end{array}$ \\
\hline$h-\mathrm{BN}$ & 230 & $30 / 15 / 55$ \\
\hline $\mathrm{SiO}_{2}$ & 286 & $30 / 15 / 55$ \\
\hline Aerosil 380 & 269 & $30 / 15 / 55$ \\
\hline $\mathrm{SiC}$ & 323 & $30 / 15 / 55$ \\
\hline Quartz wool & 297 & $30 / 15 / 55$ \\
\hline $\mathrm{BNOH}^{27}$ & 184 & $1 / 1.5 / 3.5$ \\
\hline$h-\mathrm{BN}^{28}$ & 192 & $1 / 1 / 9$ \\
\hline$h-\mathrm{BN}^{29}$ & 180 & $1 / 1.5 / 3.5$ \\
\hline$h-\mathrm{BN}^{14}$ & 253 & $30 / 15 / 55$ \\
\hline
\end{tabular}




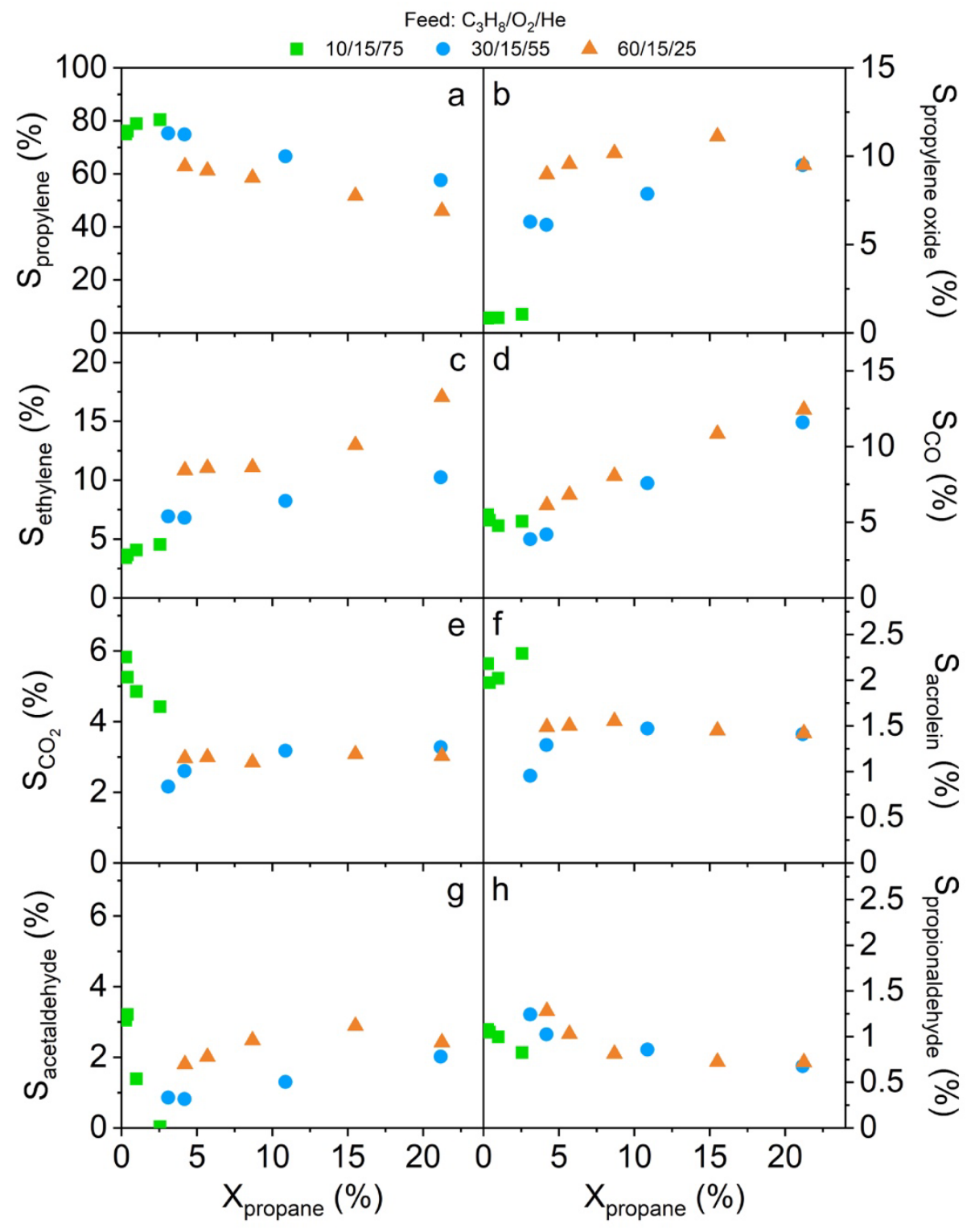

Extended Data Fig. 1: Product selectivity in the oxidation of propane using three different feeds over $\mathrm{SiO}_{2}$.

$\mathbf{a}$, propylene, b, propylene oxide, $\mathbf{c}$, Ethylene, $\mathbf{d}, \mathrm{CO}, \mathbf{e}, \mathrm{CO}_{2}, \mathbf{f}$, acrolein, $\mathbf{g}$, acetaldehyde, and $\mathbf{h}$, propionaldehyde measured for three different feed compositions as indicated in the legend on top; Reaction conditions: Mass of filling material $=666 \mathrm{mg}, \mathrm{T}=490^{\circ} \mathrm{C}, \mathrm{W} / \mathrm{F}=1.6$ to $6.0 \mathrm{~g} \mathrm{~s} \mathrm{ml}^{-1}, \mathrm{Feed}\left(\mathrm{C}_{3} \mathrm{H}_{8} / \mathrm{O}_{2} / \mathrm{He}\right)=$ 10/15/75 (square symbols), 30/15/55 (circle symbols), 60/15/25 (triangle symbols); Conversion of $\mathrm{O}_{2}$ reaches $100 \%$ at $\mathrm{W} / \mathrm{F}=6.0 \mathrm{~g} \mathrm{~s} \mathrm{ml}^{-1}$. 

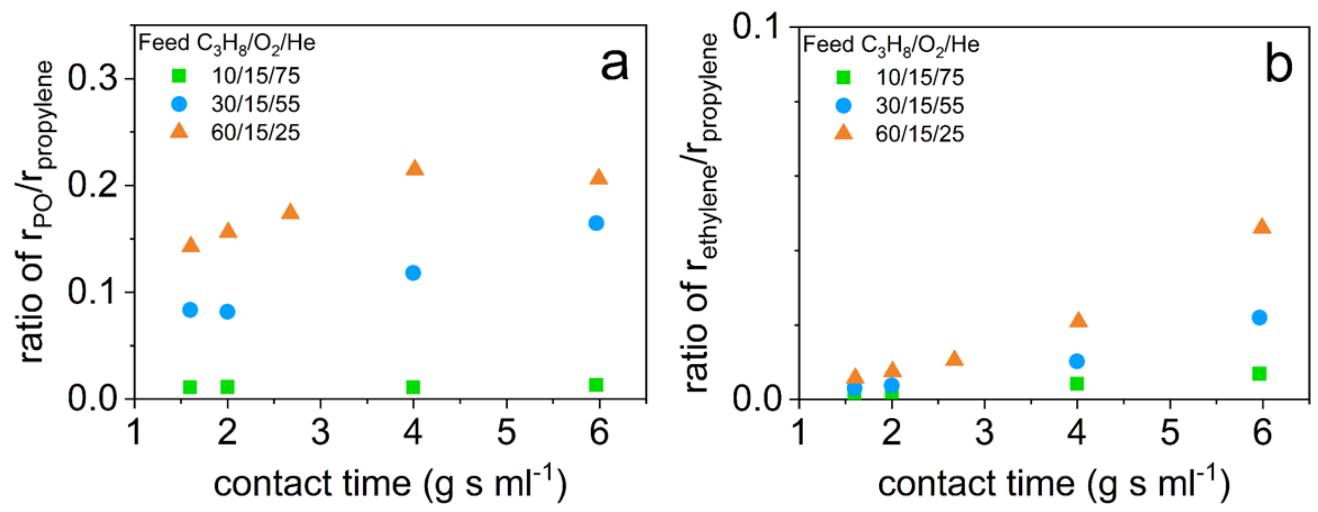

\section{Extended Data Fig. 2: Impact of the propane concentration on the reaction rates.}

a, Ratio of $r_{\mathrm{PO}} / r_{\text {propylene }}$ and, $\mathbf{b}, r_{\text {ethylene }} / r_{\text {propylene }}$ measured for $\mathrm{SiO}_{2}$ as a function of $\mathrm{W} / \mathrm{F}$ at $490^{\circ} \mathrm{C}$ in three different feeds as indicated in the legend; Mass of $\mathrm{SiO}_{2}=666 \mathrm{mg}$; Feed $\left(\mathrm{C}_{3} \mathrm{H}_{8} / \mathrm{O}_{2} / \mathrm{He}\right)=10 / 15 / 75$, $30 / 15 / 55$, and $60 / 15 / 25$.

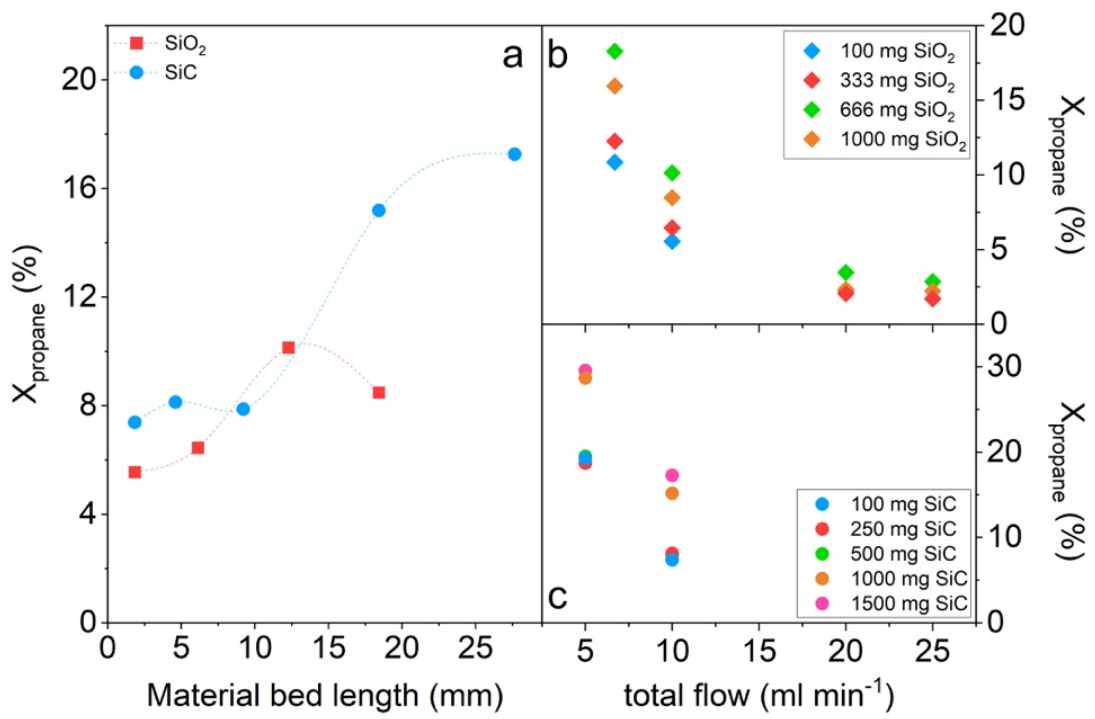

Extended Data Fig. 3: Analysis of the contribution of interfacial reactions and diffusion limitations.

a, Propane conversion as a function of the material bed hight; $\mathrm{T}=490^{\circ} \mathrm{C}, \mathrm{F}=10 \mathrm{ml} \mathrm{min}^{-1}$, Feed $\left(\mathrm{C}_{3} \mathrm{H}_{8} / \mathrm{O}_{2} / \mathrm{He}\right)=30 / 15 / 55$; Conversion of propane as a function of the total flow measured with $\mathrm{b}, \mathrm{SiO}_{2}$ and, $\mathbf{c}, \mathrm{SiC}$ (b) as filling materials; $\mathrm{T}=490^{\circ} \mathrm{C}$, flow $=4$ to $25 \mathrm{ml} \mathrm{min}^{-1}$, Feed $\left(\mathrm{C}_{3} \mathrm{H}_{8} / \mathrm{O}_{2} / \mathrm{He}\right)=30 / 15 / 55$. 


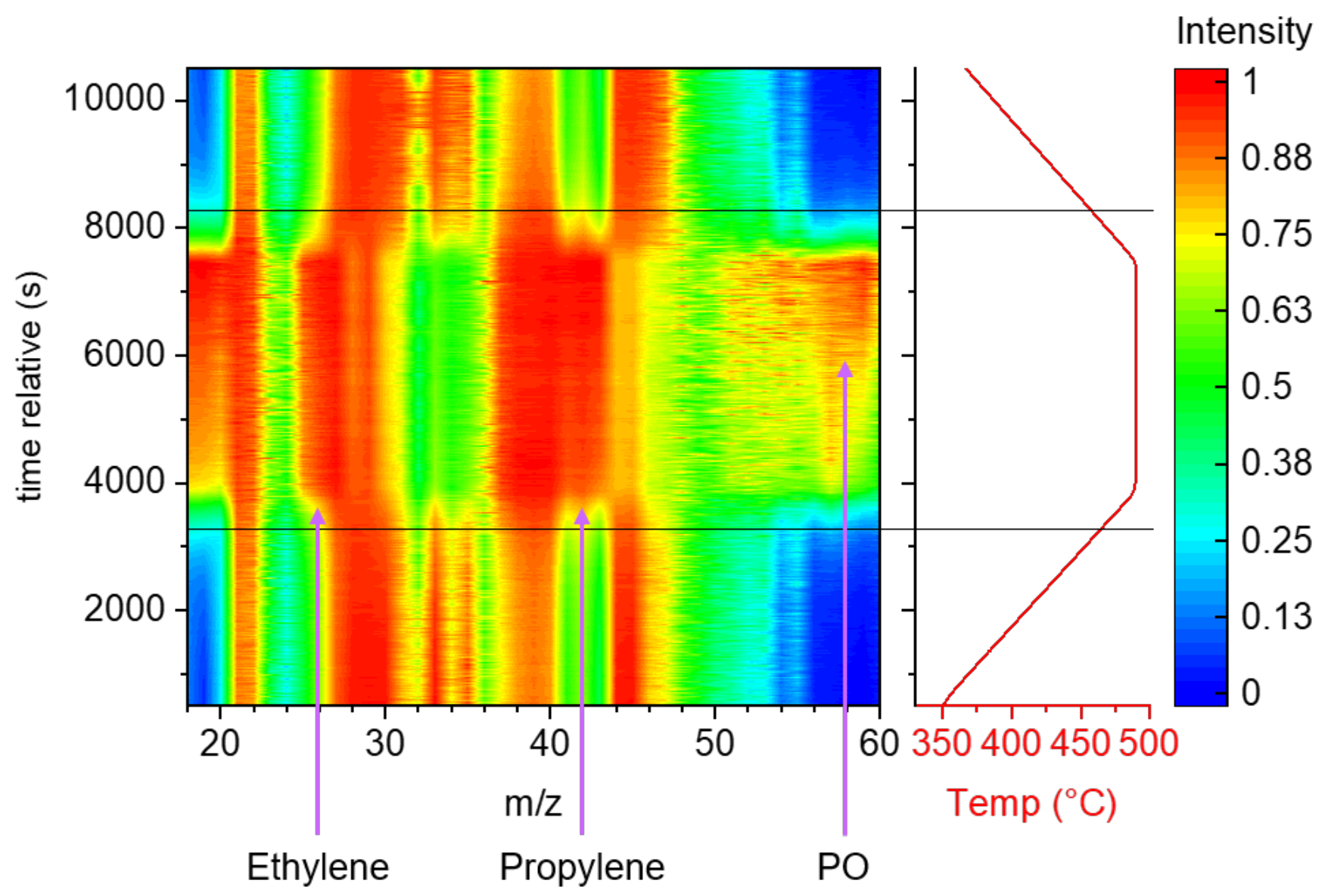

Extended Data Fig. 4: Temperature programmed reaction using $h$-BN as filler.

Temperature range: $350{ }^{\circ} \mathrm{C}$ to $490{ }^{\circ} \mathrm{C}$; Mass-to-charge ratios $\mathrm{m} / \mathrm{z} 18$ to 60 were recorded; Total flow $=10$ $\mathrm{ml} \mathrm{min}-1, \mathrm{~m}=665 \mathrm{mg} ;$ Feed $\left(\mathrm{C}_{3} \mathrm{H}_{8} / \mathrm{O}_{2} / \mathrm{He}\right)=30 / 15 / 55 ;$ Heating rate $2.5 \mathrm{~K} \mathrm{~min}^{-1}$. 
norm.

Intensity

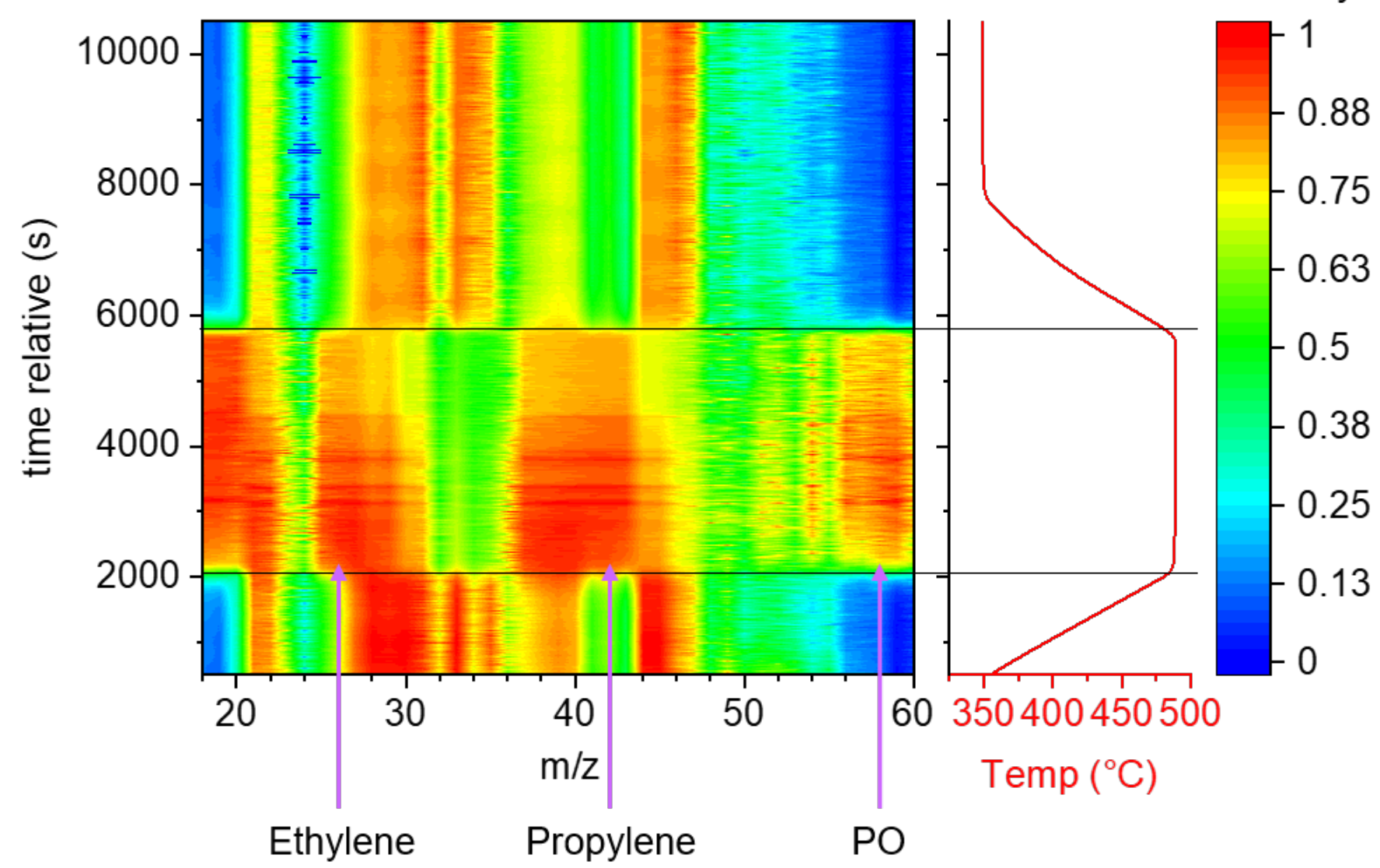

Extended Data Fig. 5: Temperature programmed reaction using $\mathrm{SiO}_{2}$ as filler and faster heating rate.

Temperature range: $350{ }^{\circ} \mathrm{C}$ to $490{ }^{\circ} \mathrm{C}$; Mass-to-charge ratios $\mathrm{m} / \mathrm{z} 18$ to 60 were recorded; Flow $=10 \mathrm{ml}$ $\min ^{-1}, \mathrm{~m}=670 \mathrm{mg}$; Feed $\left(\mathrm{C}_{3} \mathrm{H}_{8} / \mathrm{O}_{2} / \mathrm{He}\right)=30 / 15 / 55$; Heating rate $5 \mathrm{~K} \mathrm{~min}^{-1}$. 


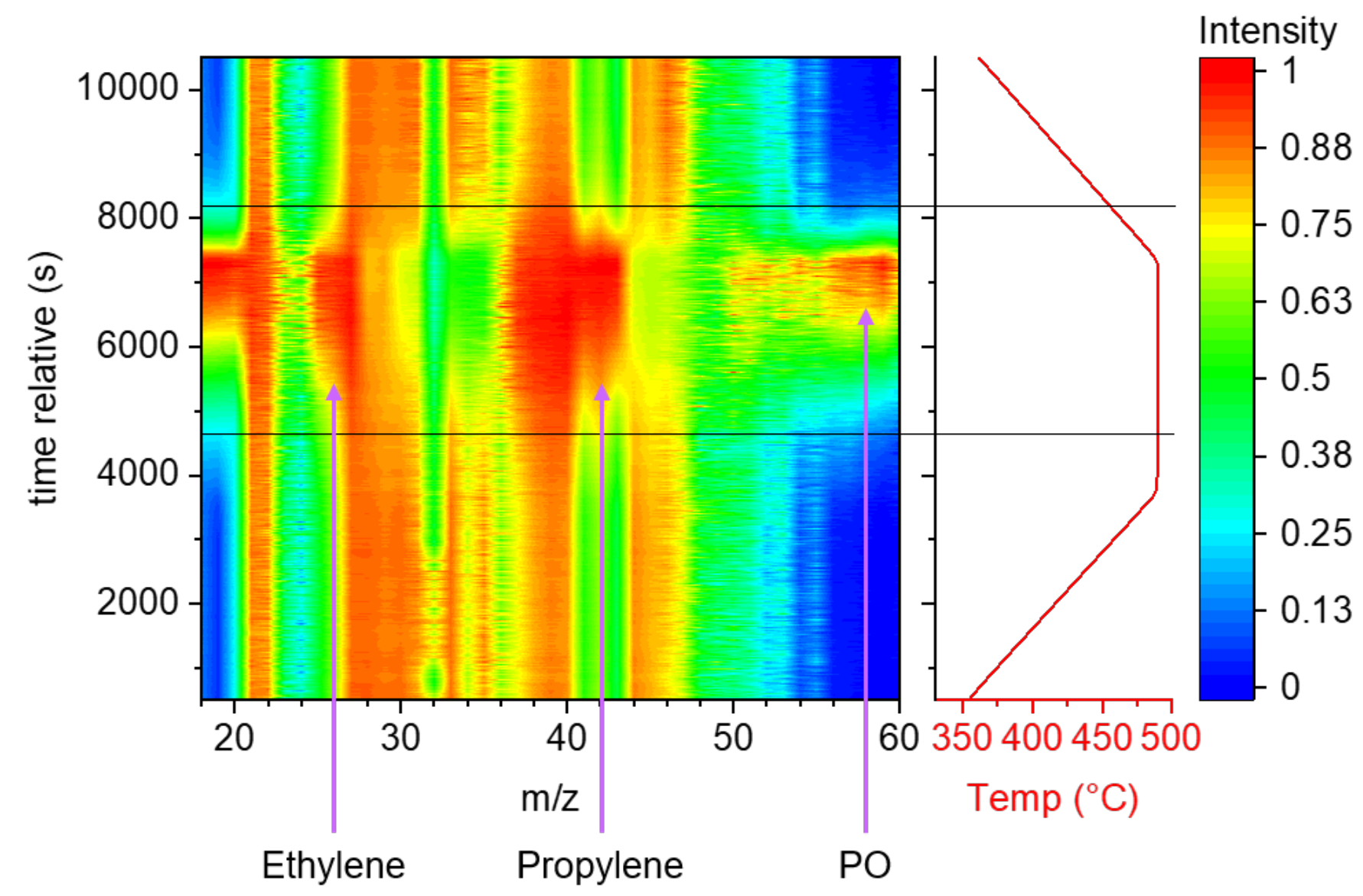

Extended Data Fig. 6: Temperature programmed reaction in an empty reactor.

Temperature range: $350{ }^{\circ} \mathrm{C}$ to $490{ }^{\circ} \mathrm{C}$; Mass-to-charge ratios $\mathrm{m} / \mathrm{z} 18$ to 60 were recorded; Flow $=10 \mathrm{ml}$ $\min ^{-1}$, Feed $\left(\mathrm{C}_{3} \mathrm{H}_{8} / \mathrm{O}_{2} / \mathrm{He}\right)=30 / 15 / 55 ;$ Heating rate $2.5 \mathrm{~K} \mathrm{~min}^{-1}$. 


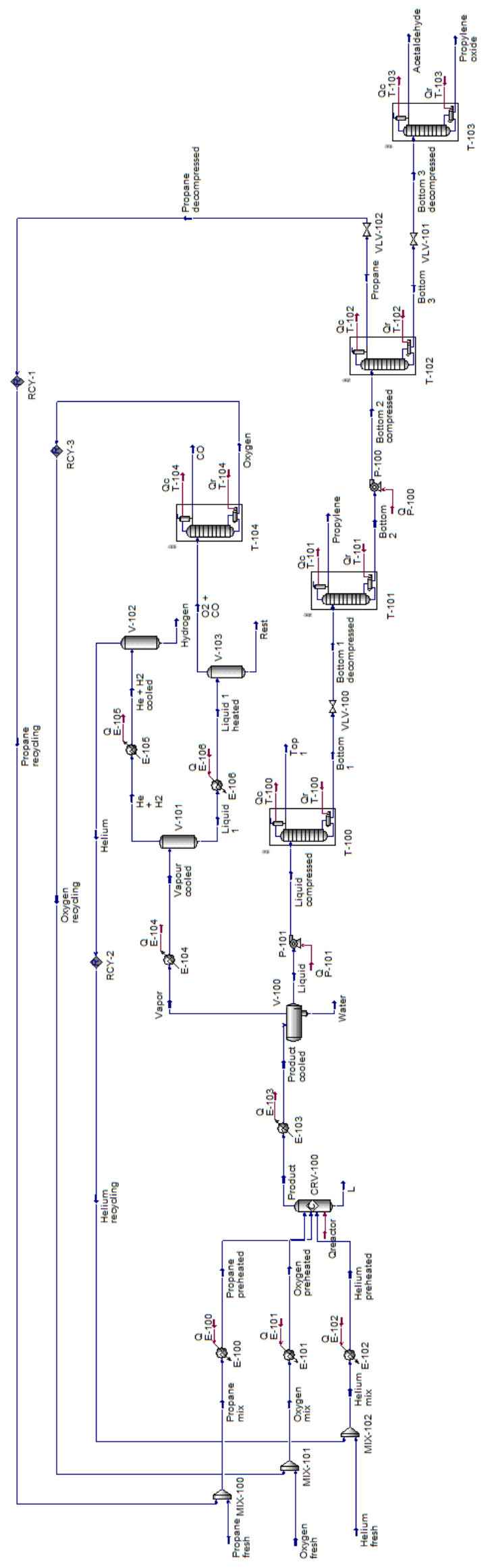

Extended Data Fig. 7: Aspen HYSYS flow-sheet for direct oxidation of propane to propylene oxide. 